\title{
THE EVALUATION OF CINNAMON EXTRACT EFFECTS ON THE INTESTINAL ESCHERICHIA COLI AND ITS RECOMPENSE
}

\author{
Chandana $\mathbf{S} 1$, Talluri Rameshwari $\mathbf{K} \mathbf{R}^{2}$ and Sumana $\mathbf{K}^{*}$ \\ $1,2,{ }^{*}$ Department of Microbiology, Faculty of Life Sciences, JSS Academy of Higher \\ Education and Research, S S Nagar, Mysuru, Karnataka. \\ Corresponding Author Email ID: sumana.k@jssuni.edu.in
}

\begin{abstract}
:
Escherichia coli are a Gram-negative, facultative anaerobic, rod-shaped, coliform bacterium; it belongs to the genus Escherichia that is commonly found in the lower intestine of warm-blooded animals and this is an opportunistic microorganism which turns out to be pathogenic leading to multiple types of diseases such as urinary tract infections, traveler's diarrhea, bacteremia and cholecystis. In India 386,600 deaths are estimated annually by the infection caused by E.coli. The drugs which are in use for the treatment of E.coli are ampicillin, norfloxacin, gentamicin, cotrimoxazole, augmentin, ciprofloxacin, amoxicillin, streptomycin and nalidixic acid. But the E.coli is resistant to all of these drugs and has been converted to multiple drug resistant microorganism. As an alternative the Cinnamon extract is found to be promising one. The extraction of cinnamon through the process of aqueous extract and the solvent extraction according to the literature have proved that at the $\mathrm{pH}$ less than 2 and the temperature of $46^{0-470} \mathrm{C}$ can inhibit the growth of E.coli as it has the Cinnamaldehyde component, which acts primarily on the cell membrane by disrupting it. So, the incorporation of the cinnamon in the food can keep a check on the number of E.coli in the human intestine and can prevent from the diarrhea, urinary tract infections and other comorbidities.
\end{abstract}

Keywords: Escherichia coli, drug resistivity, Cinnamon, agar well diffusion, filter paper discs, pH, temperature, protein synthesis inhibition.

\section{INTRODUCTION:}

E.coli is a gram-negative, facultative anaerobic, rod-shaped, coliform bacterium which belongs to the genus Escherichia and is normal micro-flora of the human intestine. These are present in relatively low concentrations in the human intestine when compared to other microorganisms [34]. And these become opportunistic when the persons' immunity becomes low or when the microbial load increases due to the uptake of contaminated food or water, as reported by World Health Organization (WHO) [1]. These cause many diseases such as urinary tract infections, traveler's diarrhea, bacteremia and cholecystis along with ulcers in the intestine.
In India 386,600 deaths are reported annually by the infection caused by E.coli [35]. The children below five years of age groups are more susceptible to the E.coli infection among all the age groups [36]. The diaherria caused by the E.coli strain O157:H7 has no medications as the antibiotics can worsen the infection and can cause Hemolytic Uremic Syndrome [HUS] mainly causes the kidney damage, which needs frequent hemodialysis. Many adverse effects of diaherria include the malnutrition. In India per year 3 lakh children die from diaherria, among which the more susceptible are from the age groups below 5. According to the report of Global Hunger Index (GHI) 2020, India was ranked 102 among 117 countries surveyed. This report analysis that, the malnutrition rate in India 
makes the children more prone to the diaherria diseases. Children in the age group of 6-12 months are more susceptible due to their illdeveloped immune system. Fatality rate increases due to this [38]. In case of the UTI, combinations of drugs are used along with nitrofurantoin. The UTI caused by E.coli are more in females than in males, due to anatomical variation, and the age groups more susceptible are 15-29 years of age in females and in males it is above 46 years of age group [37].

\section{MATERIAL \& METHODS:}

\subsection{The drugs used in treating the E.coli infection}

The drug of choice for treating the E.coli related infections include ampicillin, norfloxacin, gentamicin, cotrimoxazole, ciprofloxacin, amoxicillin, streptomycin and nalidixic acid. But for treating the diaherria it is usually suggested to drink the electrolyte rich water or plenty of normal water in order to balance the electrolytes lost from the body.

\subsubsection{Drug resistivity in E.coli}

The drug resistivity in E.coli has increased over the years and the first line antibiotics such as ampicillin and gentamicin are of low use in recent scenario. The changing trends of E.coli when observed in the year 2005 were $70 \%$ for ampicillin and 85 for gentamicin. Where the multiple drug resistivity was $12 \%$ [39]. This is due to the excessive use of the antibiotics along with not completing the full course of the prescribed medications. This has led to the increase in the spectrum of beta-lactamase ring, which has led to the multiple drug resistance. The drugs prescribed for the UTI include nitrofurantoin and fluoroquinolone, as other drugs are not effective towards reducing E.coli infection due to the bacteria's resistivity [40].

\subsubsection{Plant source as an alternative}

In order to overcome this, multiple combinations of drugs are used to treat all kinds of E.coli infections [41]. Over the time the bacterium might be resistant to all these combinations. So the plant source medicines, which have the antimicrobial properties, can be used as an alternative to this problem $[2,42]$.

\subsection{Cinnamomum verum}

Cinnamomum verum (Cinnamon) is an effective spice found in the Indian history, which is extracted from the bark of the tree and due to its varied applicability it is used in the medicinal, cosmetic and food industry [2, 3]. Cinnamaldehyde (Figure1) [6] -a compound present extensively in Cinnamon- is an essential oil component and is an aromatic compound with a mono-substituted benzene ring with an aldehyde group [7]. It plays a role in reducing the blood pressure, fat deposited in the adipose tissue, reducing the glucose level and inhibiting the growth of E.coli in the human intestine [4, 5].

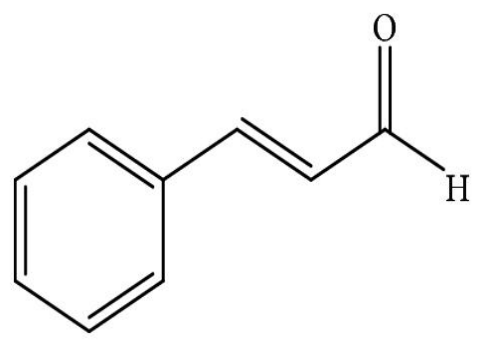

\section{Figure 1: Structure of Cinnamaldehyde [7]}

Some studies have proved that by reducing or inhibiting the in-vitro polymerization process and thereby degenerating the cells, cinnamaldehyde reduces/inhibits the cell division of E. coli in the human intestine $[7,8]$. But the main component over here is the presence of Aldehyde group, which binds to the DNA proteins through the amines and in turn they interfere in the normal function of the bacterium. The study finds that, the action of cinnamon is different in different concentrations: when used in small concentrations, it inhibits the enzymes involved the process of cytokinesis. When used at sub- 
lethal concentrations, it acts as an ATPase inhibitor. And when used in high concentrations the cinnamaldehyde acts on the cell membrane and disrupts it [43]. Not just the sub-lethal concentrations inhibit the ATPase concentrations, but, the amount of cinnamaldehyde present also contributes to the disruption (681-1362 $\mu \mathrm{g} / \mathrm{ml}$ ) [44]. Increasing the concentration of cinnamaldehyde increases the lethality of the bacterium $(0.31 \mathrm{mg} / \mathrm{g})$ [45].

As the cinnamon has these antimicrobial properties it is used by following some of the methods such as: the solvent extraction methodwhich mainly includes the extraction of cinnamon by adding ethanol [9]. The second one is aqueous extract where the water is added to the cinnamon [13, 14]. And the third method is the powdered form of cinnamon which is directly added to the microbe medium [6]. Along with these by varying the $\mathrm{pH}$ and temperature of the cinnamon, can produce the promising results.

\section{IMPORTANT TECHNIQUES}

\subsection{Preparation of Inoculum:}

- The sample was prepared by using the Escherichia coli (ATCC 25404TM) inoculum and growing it in the Luria-Bertani (LB) broth at $37^{\circ} \mathrm{C}$ for 24 hours.

- Required amount of sample was taken and spread on LB plates. This was left for drying for 15 minutes [46].

\subsection{Solvent Extract Method of Cinnamon:}

Solvent extraction is a process of separating two immiscible liquids, out of which one is water and the other is an organic solvent. This process was first developed for the analytical chemistry, so that all the metallic elements can be virtually separated. It is also known as Liquid -Liquid extraction. Steam distillation process is one of the types of solvent extraction, which is cheaper and more effective when compared to other methods [28]. This method is also considered as the safest method and the wastage of the products is limited over here.

\subsubsection{Steam Distillation Process:}

- $25.5 \mathrm{~g}$ of cinnamon sticks were powdered and added to the round conical flask containing $100 \mathrm{ml}$ of water [47].

- To this solution 3-4 drops of Dichloromethane (DCM) was added and shaken vigorously to mix with the essential oil.

- Then the flask was tilted in order to separate the layer of dichloromethane and the distillate.

- After this the organic layer was transferred to a test-tube and this procedure of separation of DCM and collection of the organic layer was repeated three to four times.

- The test-tube containing the organic substance was kept in a boiling water bath until the DCM evaporates.

- Then the dark-yellowish solution of the cinnamon was obtained and was transferred into a micro-centrifuge tube and refrigerated. (Figure 3) [20]

- Required concentration of the extract was taken for further testing, that is the sensitivity test.

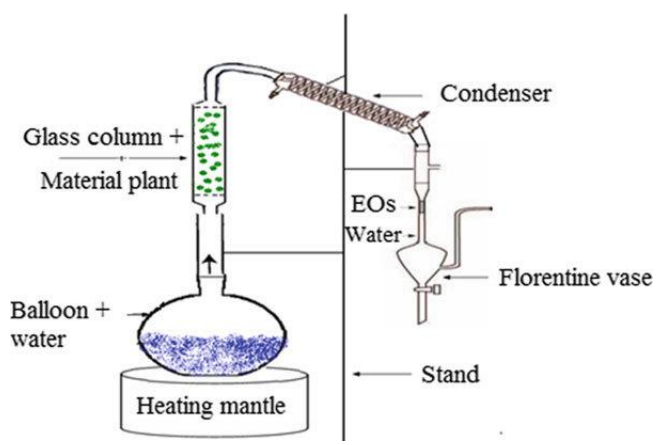

Figure 3: Steam distillation process [20] 


\subsubsection{Alcohol Dilutant Method:}

- $70 \%$ ethyl alcohol was used as a dilutant in this paper [46].

- The series of dilutants of cinnamon essential oil (EO) was prepared in the order 0, 0.5, 1, 2 and 4\%.

- Sterile paper discs were prepared and were placed in each dilutant and were left to dry.

- Each different sterile paper discs were placed in the respective petriplate containing the media along with E.coli, and were incubated at $37^{\circ} \mathrm{C}$ for 24 hours for the observation of inhibition zone.

\subsection{Sensitivity testing:}

Sensitivity testing is the method which is used to test the sensitivity of the bacterium towards the antibiotic. It helps in the identification of the proper drugs and also helps in understanding the nature of the bacterium. It is usually determined by the size of the zone of inhibition. The zone of inhibition occurs when the antimicrobial substance is equal to or greater than the minimum inhibitory concentration, which acts upon the bacterium which has been inoculated on the medium [29].

\subsubsection{Agar well diffusion method:}

- The 40-micro liter of inoculums was swabbed in the solidified MHA medium and cooled for 15 minutes.

- $8 \mathrm{~mm}$ diameter wells were created by using sterile stainless steel borer.

- The prepared cinnamon extract of varied concentration $(105,20 \% \ldots . . . .90 \%)$ were poured into the wells.

- This was incubated for 24 hours at $34^{\circ} \mathrm{C}$.

- After incubation the diameter of the zone of inhibition of various concentrations of extracts were measured.
2.3.2
Sensitivity
testing
using

- The antibiotic discs, such as, ampicillin and streptomycin were added in $10 \mathrm{mcg}$ concentration to the petriplates containing the inoculum and the medium.

- Then the petriplates were incubated in for $37^{\circ} \mathrm{C}$ for 24 hours.

\subsection{Determination of Minimal Inhibitory Concentration (MIC):}

Minimal inhibitory concentration is the concentration at which there will be no growth of microbes due to the activity of the antimicrobial agent after overnight incubation.

\subsubsection{Broth dilution method:}

- The MHA media was added to ten test tubes and the E.coli (40 micro liter) was added in the same concentration to all the test tubes.

- Then the serial diluted concentration of the cinnamon extract was added to the test tubes as $0.1,0.2 \ldots \ldots \ldots \ldots \ldots . .1 \mathrm{ml}$.

- Then the test tubes were kept for incubation overnight to get the required result.[21]

\subsection{Varying the parameters of growth:}

The parameters such as $\mathrm{pH}$ and temperature can play a major role in altering the growth of the microorganisms at the same time they may also inhibit the effect of cinnamon.

\subsubsection{Temperature}

- The cinnamon of varied concentrations had been kept at the high temperatures (usually in the pressure cooker as the food is usually cooked in that).

- After taking out from the pressure cooker, the cinnamon extract was added to the swabbed E.coli on the MHA medium.

- The petriplates were incubated for 24-48 hours and kept at $37^{\circ}$ and observed for results.

\subsection{2 pH}

- The cinnamon extract was diluted to the high $\mathrm{pH}$ and the low $\mathrm{pH}$ value by adding 
certain amount of acidic and basic solutions to the extract.

- Then the acidic solution was added to the swabbed E.coli MHA medium on one petriplate.

- In another petriplate the basic solution of the extract was added and in a third petriplate the neutral $\mathrm{pH}$ extract of cinnamon was added.

- Further all the plates were kept for incubation at the same temperature of $37^{\circ} \mathrm{C}$ for 24-48 hours.

- Then observed for the results.[22,26]

\section{ADJECTIVE STATEMENT}

Here the experiments were performed in order to reduce the number of microbes, that is, E.coli, so as to get rid of the infection. Due to the excessive use allopathic medicines the bacteria began to develop resistance which is widely known as multiple drug resistance. So the researchers had performed the above mentioned study by using the Ayurvedic components and check their ability to inhibit the growth of microbes. The study also reveals that not just Cinnamon, but also wide number of spices in required concentration help in inhibiting the growth of microbes in their own way. The effect of Cinnamon on E.coli has wide applications along with inhibiting the microbial growth. These include reducing the blood sugar in diabetic patients and so on.

From the studies of Andrews JM (2001) [21] we will come to know the use of essential oil of cinnamon, which can reduce the growth of microbe. Thus essential oils are very useful and are not harmful as such. So these can be used in the preservation of food, especially the canned foods. Or else consuming the cinnamon water after having the fast foods can help to reduce the microbial load. But as per the studies done by Spisni E, et al., (2020) [18]the concentrations of the cinnamon added is also very important, as the increased load of it can harm the intestinal lining and may lead to some other infections. So it is prescribes to use around or more than $90 \%$ of cinnamon to reduce the intestinal E.coli and it is confirmed by the studies of Raeisi M, et al., (2015) [15]. Alteration of certain parameters required by the microbial growth can yield great results and further enhance its use. The varying level of $\mathrm{pH}$ can yield us the best results as proved and suggested by Chen YC, et al., (2003) [22].

The major parameters here are the temperature and $\mathrm{pH}$. Altering them according to the concentration of the microbe present can lead very good results. Getting the promising results can lead to the accuracy of the experiment which can be implemented in further processes.

\section{RESULTS \& DISCUSSION RESULTS}

\section{Antibiotic Sensitivity Test}

The solvent extraction method is a promising one, in which, higher the concentration of the solvent of cinnamon added more will be the inhibition rate [47]. In the alcohol dilution method, the zone of inhibition was found more in the higher concentration, rather than in the lower concentration. Hence the concentration at $4 \%$ of the Cinnamon EO can be effective against the E.coli rather than at $2 \%$ of the concentration. In the concentrations 0 and $0.5 \%$ the zone of inhibition was with little difference. The zone of inhibition was $5.1 \mathrm{~mm}$, whereas in $4 \%$ concentration it was $7.1 \mathrm{~mm} \mathrm{[46].}$

The zone of inhibition formed when the antibiotics such as ampicillin and streptomycin used was $2.3 \mathrm{~mm}$, which is less than the $2 \%$ concentration of Cinnamon EO [46]. This will 
reveal that, the cinnamon is more effective against the gut E.coli rather than the synthetic antibiotics.

\section{Minimal Inhibitory Concentration (MIC):}

The MIC of the cinnamon on gut E.coli was found to be $4.88 \mu \mathrm{g} / \mathrm{ml}$ and the inhibition diameter was $29.0 \mathrm{~mm}$. Whereas for ampicillin and streptomycin the MIC values were found to be $0.31 \mu \mathrm{g} / \mathrm{ml}$ and $3.13 \mu \mathrm{g} / \mathrm{ml}$ respectively. And the inhibition diameter was $20 \mathrm{~mm}$ and $15.3 \mathrm{~mm}$ [48].

\section{Temperature and $\mathrm{pH}$ :}

As the temperature and $\mathrm{pH}$ are the two main constituents for E.coli growth, differing these can alter the amount of E.coli present in the gut microflora. Higher the temperature and lower the $\mathrm{pH}$ the effect of cinnamon will be more on E.coli. As the outside factors sometimes contribute to the increase in the number of gut E.coli, it is necessary to use these two factors to prevent the former's growth [22, 26].

\section{DISCUSSION:}

The Escherichia coli can be destroyed by altering the $\mathrm{pH}$ of the medium, so that if the intracellular $\mathrm{pH}$ gets reduced then the destruction of Escherichia coli occurs [22]. The Escherichia coli can be killed or its activity can be halted/inhibited by increasing the concentrations of the Cinnamon oil used [15]. Higher the concentration of the oil used more will be the destruction. The medicinal herbs/plants including the cinnamon plant has the competence to reduce the harmful effect of E.coli on the intestinal colon. The traditional medicines and spices can be preferred in present era of allopathy [3].

The MIC of the synthetic antibiotics such as ampicillin and streptomycin was $20 \mathrm{~mm}$ and $15.3 \mathrm{~mm}$ respectively, but for the cinnamon it was $4.88 \mu \mathrm{g} / \mathrm{ml}$ [48]. This indicates that the cinnamon is more effective against the gut E.coli. Whereas some results of the same paper suggest that by using the combination of the pre-used drugs such as ampicillin and streptomycin along with cinnamon oil can reduce the gut E.coli negative effect to some extent. This was preferred due to the multidrug resistivity of E.coli strains. The value of zone of inhibition varies according to the type of strain of E.coli present [33].

The stool samples collected in India showed that more resistant was towards ampicillin and $74 \%$ resistant was MDR in the E.coli isolated [30]. But when studied in the major countries, the data provides that, in these countries the gut E.coli strains were resistant to amoxicillin and ciprofloxacin [49].

\section{CONCLUSION}

Due to the MDR of the gut E.coli to almost all the drugs which were prevalent since many years, it is suggested to use the plant sources such as cinnamon as an antimicrobial drug. Along with these the combinations of the drugs can be used, but this may also lead to the MDR. So cinnamon is preferred due to its less/no side-effects on the human health.

Through the studies it was found that different concentrations of the cinnamon have different effects on the E.coli growth. If the concentrations of the cinnamon extract are increased to a greater extent the effect is more in terms of destruction of E.coli. To suppress E.coli in the human intestine, higher concentrations such as $90 \%$ $100 \%$ of cinnamon powder are required. As the concentration of the EO is increased, the zone of inhibition also increases. It is same for the temperature. But the acidic $\mathrm{pH}$ favors the reduction of E.coli in the intestine. Hence more the concentration of various cinnamon extracts more will be the effect.

\section{ACKNOWLEDGMENT}

I thank Department of Microbiology, Faculty of Life Sciences, JSS Academy of Higher Education \& Research, S S Nagar, Mysuru- 570015 for support the work.

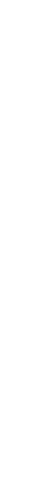

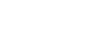




\section{REFERENCES:}

Leung E, Weil DE, Raviglione M, Nakatani H. The WHO policy package to combat antimicrobial resistance. Bulletin of the World Health Organization. 2011;89:390-2

Nazzaro F, Fratianni F, De Martino L, Coppola R, De Feo V. Effect of essential oils on pathogenic bacteria. Pharmaceuticals. 2013 Dec;6(12):1451-74.

Mukhtar S, Ghori I. Antibacterial activity of aqueous and ethanolic extracts of garlic, cinnamon and turmeric against Escherichia coli ATCC 25922 and Bacillus subtilis DSM 3256. International Journal of applied biology and pharmaceutical Technology. 2012;3(2):131-6.

Ranasinghe P, Pigera S, Premakumara GS, Galappaththy P, Constantine GR, Katulanda P. Medicinal properties of 'true'cinnamon (Cinnamomumzeylanicum): a systematic review. BMC complementary and alternative medicine. 2013 Dec 1;13(1):275.

Ooi LS, Li Y, Kam SL, Wang H, Wong EY, Ooi VE. Antimicrobial activities of cinnamon oil and cinnamaldehyde from the Chinese medicinal herb Cinnamomum cassia Blume. The American journal of Chinese medicine. 2006;34(03):511-22.

Rao PV, Gan SH. Cinnamon: a multifaceted medicinal plant. Evidence-Based Complementary and Alternative Medicine. 2014 Jan $1 ; 2014$.

Seraj Z, Seyedarabi A. The role of Cinnamaldehyde and Phenyl ethyl alcohol as two types of precipitants affecting protein hydration levels. International Journal of Biological Macromolecules. 2020 Mar 1;146:705-15.

Tu XF, Hu F, Thakur K, Li XL, Zhang YS, Wei ZJ. Comparison of antibacterial effects and fumigant toxicity of essential oils extracted from different plants. Industrial Crops and Products. 2018 Nov 15;124:192-200.

Flies A, Ermak TH. Lipopolysaccharide-Binding Protein (LBP) as an Indicator of Disease States in Multiple Species. pathways.;3:6.

Nabavi SF, Di Lorenzo A, Izadi M, SobarzoSánchez E, Daglia M, Nabavi SM. Antibacterial effects of cinnamon: From farm to food, cosmetic and pharmaceutical industries. Nutrients. 2015 Sep;7(9):772948.

Zhang Y, Liu X, Wang Y, Jiang $\mathrm{P}$, Quek S. Antibacterial activity and mechanism of cinnamon essential oil against Escherichia coli and Staphylococcus aureus. Food Control. 2016 Jan 1;59:282-9.

Wardatun S, Rustiani E, Alfiani N, Rissani D. Study effect type of extraction method and type of solvent to cinnamaldehyde and trans-cinnamic acid dry extract cinnamon (Cinnamomumburmanii [Nees\& T, Nees] Blume). Journal of Young Pharmacists. 2017;9(1):S49.

Parvazi S, Sadeghi S, Azadi M, Mohammadi M, Arjmand M, Vahabi F, Sadeghzadeh S, Zamani $Z$. The effect of aqueous extract of cinnamon on the metabolome of Plasmodium falciparum using $1 \mathrm{HNMR}$ spectroscopy. Journal of tropical medicine. 2016 Jan 20;2016.

Koppikar SJ, Choudhari AS, Suryavanshi SA, Kumari S, Chattopadhyay S, KaulGhanekar R. Aqueous Cinnamon Extract $(\mathrm{ACE}-\mathrm{c})$ from the bark of Cinnamomumcassiacauses apoptosis in human cervical cancer cell line (SiHa) through loss of mitochondrial membrane potential. BMC cancer. 2010 Dec $1 ; 10(1): 210$.

Raeisi M, Tajik H, Yarahmadi A, Sanginabadi S. Antimicrobial effect of cinnamon essential 
oil against Escherichia coli and Staphylococcus aureus. Health Scope. 2015 Nov $1 ; 4(4)$.,

Sun D, Lv J, Chen W, Li S, Guo Y, Bian Z, Yu C, Zhou H, Tan Y, Chen J, Chen Z. Spicy food consumption is associated with adiposity measures among half a million Chinese people: the China Kadoorie Biobank study. BMC Public Health. 2014 Dec 1;14(1):1293.

Dušan F, Marián S, Katarína D, Dobroslava B. Essential oils-their antimicrobial activity against Escherichia coli and effect on intestinal cell viability. Toxicology in vitro. 2006 Dec 1;20(8):1435-45.

Spisni E, Petrocelli G, Imbesi V, Spigarelli R, Azzinnari D, DonatiSarti M, Campieri M, Valerii MC. Antioxidant, Anti-Inflammatory, and Microbial-Modulating Activities of Essential Oils: Implications in Colonic Pathophysiology. International Journal of Molecular Sciences. 2020 Jan;21(11):4152.

Oh SY, Yun W, Lee JH, Lee CH, Kwak WK, Cho JH. Effects of essential oil (blended and single essential oils) on anti-biofilm formation of Salmonella and Escherichia coli. Journal of animal science and technology. 2017 Dec;59(1):1-5.

Sahraoui N, Boutekedjiret C. Innovative process of essential oil extraction: steam distillation assisted by microwave. InProgress in Clean Energy, Volume 12015 (pp. 831-841). Springer, Cham.

Andrews JM. Determination of minimum inhibitory concentrations. Journal of antimicrobial Chemotherapy. 2001 Jul 1;48(supp1_1):5-16.

Chen YC, Chiu CP, Chen BH. Mutagenicity of fumes from fried chicken legs. Journal of food protection. 2003 Jul;66(7):1269-76.,

Awad HM, Kamal YE, Aziz R, Sarmidi MR, ElEnshasy HA. Antibiotics as microbial secondary metabolites: Production and application. JurnalTeknologi. 2012 Sep 15;59(1).

Rahman S, Parvez AK, Islam R, Khan MH. Antibacterial activity of natural spices on multiple drug resistant Escherichia coli isolated from drinking water, Bangladesh. Annals of clinical microbiology and antimicrobials. 2011 Dec 1;10(1):10.

Liu Q, Meng X, Li Y, Zhao CN, Tang GY, Li HB. Antibacterial and antifungal activities of spices. International journal of molecular sciences. 2017 Jun;18(6):1283

Oussalah M, Caillet S, Lacroix M. Mechanism of action of Spanish oregano, Chinese cinnamon, and savory essential oils against cell membranes and walls of Escherichia coli O157: H7 and Listeria monocytogenes. Journal of food protection. 2006

May;69(5):1046-55.

Khan AU, Ali S, Rehman AU, Ali H, Ahmad T, Waqar M, Niaz Z. Antibacterial Activity of Nigella sativa and Piper nigrum. Asian Journal of Natural and Applied Sciences. 2013 Dec;2(4):173-9.

Wong YC, Ahmad-Mudzaqqir MY, WanNurdiyana WA. Extraction of essential oil from cinnamon (Cinnamomumzeylanicum). Oriental journal of chemistry. 2014;30(1):37.

Biemer JJ. Antimicrobial susceptibility testing by the Kirby-Bauer disc diffusion method. Annals of Clinical \& Laboratory Science. 1973 Mar 1;3(2):135-40.

Purohit MR, Lindahl LF, Diwan V, Marrone G, Lundborg CS. High levels of drug resistance in commensal E. coli in a cohort of children from rural central India. Scientific reports. 2019 Apr 30;9(1):1-1.

Olorunmola FO, Kolawole DO, Lamikanra A. Antibiotic resistance and virulence properties in Escherichia coli strains from 
cases of urinary tract infections. African journal of infectious diseases. 2013 Feb 18;7(1):1-7.

Khalil IA, Troeger C, Blacker BF, Rao PC, Brown A, Atherly DE, Brewer TG, Engmann CM, Houpt ER, Kang G, Kotloff KL. Morbidity and mortality due to shigella and enterotoxigenic Escherichia coli diarrhoea: the Global Burden of Disease Study 1990-2016. The Lancet Infectious Diseases. 2018 Nov 1;18(11):1229-40.

Pereira WA, Pereira CD, Assunção RG, da Silva IS, Rego FS, Alves LS, Santos JS, Nogueira FJ, Zagmignan A, Thomsen TT, LøbnerOlesen A. New Insights into the Antimicrobial Action of Cinnamaldehyde towards Escherichia coli and Its Effects on Intestinal Colonization of Mice. Biomolecules. $2021 \mathrm{Feb} ; 11(2): 302$.

Katouli M. Population structure of gut Escherichia coli and its role in development of extra-intestinal infections. Iranian journal of microbiology. 2010 Jun;2(2):59.

Aggarwal P, Uppal B, Ghosh R, Prakash SK, Rajeshwari K. Highly-resistant E. coli as a common cause of paediatric diarrhoea in India. Journal of health, population, and nutrition. 2013 Sep;31(3):409.

Gandra S, Tseng KK, Arora A, Bhowmik B, Robinson ML, Panigrahi B, Laxminarayan R, Klein EY. The mortality burden of multidrug-resistant pathogens in India: a retrospective, observational study. Clinical Infectious Diseases. 2019 Aug 1;69(4):56370.

Magliano E, Grazioli V, Deflorio L, Leuci AI, Mattina R, Romano P, Cocuzza CE. Gender and age-dependent etiology of communityacquired urinary tract infections. The scientific world journal. 2012 Jan 1;2012.
Singh A. Childhood Malnutrition in India. InPerspective of Recent Advances in Acute Diarrhea 2020 Mar 2. IntechOpen.

Kumar A, Leite AF, Maekawa LS, Kaur R, Filo SJ, Persaud P, Shaikh JD, Kichloo A, Shiwalkar N. Management of E. coli Sepsis. InE. Coli Infections-Importance of Early Diagnosis and Efficient Treatment 2020 Aug 14. IntechOpen.

Kibret M, Abera B. Antimicrobial susceptibility patterns of E. coli from clinical sources in northeast Ethiopia. African health sciences. 2011;11:40-5.

Podnecky NL, Fredheim EG, Kloos J, Sørum V, Primicerio R, Roberts AP, Rozen DE, Samuelsen $\varnothing$, Johnsen PJ. Conserved collateral antibiotic susceptibility networks in diverse clinical strains of Escherichia coli. Nature Communications. 2018 Sep 10;9(1):1-1.

Chandra H, Singh C, Kumari P, Yadav S, Mishra AP, Laishevtcev A, Brisc C, Brisc MC, Munteanu MA, Bungau S. Promising Roles of Alternative Medicine and Plant-Based Nanotechnology as Remedies for Urinary Tract Infections. Molecules. 2020 Jan;25(23):5593.

Hyldgaard M, Mygind T, Meyer RL. Essential oils in food preservation: mode of action, synergies, and interactions with food matrix components. Frontiers in microbiology. 2012 Jan 25;3:12.

Gill AO, Holley RA. Inhibition of membrane bound ATPases of Escherichia coli and Listeria monocytogenes by plant oil aromatics. International journal of food microbiology. 2006 Sep 1;111(2):170-4.

Shen S, Zhang T, Yuan Y, Lin S, Xu J, Ye H. Effects of cinnamaldehyde on Escherichia coli and Staphylococcus aureus membrane. Food Control. 2015 Jan 1;47:196-202. 
Adams VR, Johnson AK, Santos FB, Santos Jr AA. The Effect of Cinnamon Essential Oil on Escherichia coli. The FASEB Journal. 2019 Apr;33(S1):1b286-.

Wong YC, Ahmad-Mudzaqqir MY, WanNurdiyana WA. Extraction of essential oil from cinnamon (Cinnamomum zeylanicum). Oriental journal of chemistry. 2014;30(1):37.

El Atki Y, Aouam I, El Kamari F, Taroq A, Nayme K, Timinouni M, Lyoussi B, Abdellaoui A. Antibacterial activity of cinnamon essential oils and their synergistic potential with antibiotics. Journal of advanced pharmaceutical technology \& research. 2019 Apr;10(2):63.

Pormohammad A, Nasiri MJ, Azimi T. Prevalence of antibiotic resistance in Escherichia coli strains simultaneously isolated from humans, animals, food, and the environment: a systematic review and metaanalysis. Infection and drug resistance. 2019;12:1181. 